\title{
A normal-faulting seismic sequence triggered by the 2011 off the Pacific coast of Tohoku Earthquake: Wholesale stress regime changes in the upper plate
}

\author{
Aitaro Kato, Shin'ichi Sakai, and Kazushige Obara
}

Earthquake Research Institute, University of Tokyo

(Received April 8, 2011; Revised June 7, 2011; Accepted June 8, 2011; Online published September 27, 2011)

\begin{abstract}
We here show relocated hypocenters within a seismic sequence with normal faults in the northern part of Ibaraki Prefecture, triggered after the M9.0 2011 off the Pacific coast of Tohoku Earthquake. Depth-sections of the hypocenters from the center of the northern Ibaraki region to the north show an earthquake alignment dipping westwards at $40^{\circ}$ to $50^{\circ}$ at depths shallower than $10 \mathrm{~km}$. On the other hand, hypocenters from the center to the south show a cross-cutting geometry consisting of conjugate westward- and eastward-dipping planes at the same depths. The dip angles of the hypocenter alignments are roughly consistent with the nodal planes of focal mechanisms of large normal earthquakes, and exhibit optimal-orientations in terms of the frictional failure criterion. Furthermore, comparison of the focal mechanisms recorded before and after the 2011 Tohoku Earthquake suggests that the stress field abruptly changed from horizontal compression to extension in the study area. The most plausible explanation of the drastic stress changes is a significant reduction in trench-normal compressive stress compared with reduction in trench-parallel stress accompanying large horizontal extensional deformation within the overlying plate.
\end{abstract}

Key words: Normal-faulting, earthquake alignments, stress changes, the 2011 Tohoku Earthquake, doubledifference relocation.

\section{Introduction}

The 2011 off the Pacific coast of Tohoku Earthquake $M 9.0$ ruptured a fault area nearly $500 \mathrm{~km}$ along-strike length and $200 \mathrm{~km}$ down-dip width of the fault off-shore of the Tohoku region along the Japan Trench subduction zone as a huge thrust earthquake at 14:46 (JST $=$ UT + 9 hours) on March 11, 2011 (Japan Meteorological Agency (JMA)). The focal mechanism of this earthquake is a reverse fault type with a low-dipping angle, suggesting that the fault is located along the interface between the subducting Pacific plate and the overlying plate. This huge thrust earthquake has caused devastating seismic and tsunami's damage in NE Japan. Ide et al. (2011) imaged a spatio-temporal slip distribution of the 2011 Tohoku Earthquake applying finite-source modeling to global broadband seismograms. The highest cumulative slip in their model is about $30 \mathrm{~m}$ and is strongly concentrated in the shallow part of the fault. They have documented that normal faulting aftershocks in the area of high slip indicate total stress drop or dynamic overshoot on the mainshock fault plane (e.g., Hasegawa et al., 2011).

The 2011 Tohoku Earthquake triggered widespread seismicity throughout the Japanese island arc including Hokkaido and Kyushu regions. In particular, a significant increase in the shallow seismicity was observed in the days following the mainshock along the Pacific coast of

Copyright (C) The Society of Geomagnetism and Earth, Planetary and Space Sciences (SGEPSS); The Seismological Society of Japan; The Volcanological Society of Japan; The Geodetic Society of Japan; The Japanese Society for Planetary Sciences; TERRAPUB.

doi: $10.5047 /$ eps.2011.06.014
NE Japan, notably the northern part of Ibaraki Prefecture, the southern part of Fukushima Prefecture and off Choshi (Hirose et al., 2011).

In the northern part of Ibaraki Prefecture, the rate of shallow seismicity during the eight years before the 2011 Tohoku Earthquake had been extremely low ( $~ 5$ events per year). However, the rate of seismicity abruptly increased after the 2011 Tohoku Earthquake, and several large magnitude events as large as $M_{\text {jma }} 6.1$ occurred (JMA cata$\log$ ) (Fig. 1). This induced seismicity is characterized as "swarm-like" sequences without obvious mainshocks with Omori-law-abiding aftershocks. The most striking feature of the induced seismicity is that the focal mechanisms reveal normal faulting with a $T$-axis orientated in a roughly E-W direction (Fig. 1(b)). In NE Japan, it has been reported previously that trench-normal compressive stresses, aligned in the approximate direction of plate convergence, tend to dominate stress field over broad regions (e.g., Kato et al., 1998; Wang and Suyehiro, 1999; Townend and Zoback, 2006). However, the stress field revealed in the northern Ibaraki is horizontally extensive, not compressive.

Temporal stress changes above a subducting plate can provide important information on stress interactions between the subducting and overlying plates (e.g., Wesson and Boyd, 2007; Saiga et al., 2011). This is therefore crucial to understand the unusual sequence of normal faults. In this paper, we have relocated earthquakes in the northern part of Ibaraki Prefecture that occurred immediately after the 2011 Tohoku Earthquake using the double-difference relocation method (Waldhauser and Ellsworth, 2000) and report here on a drastic change in the stress field induced by large ex- 
(a)

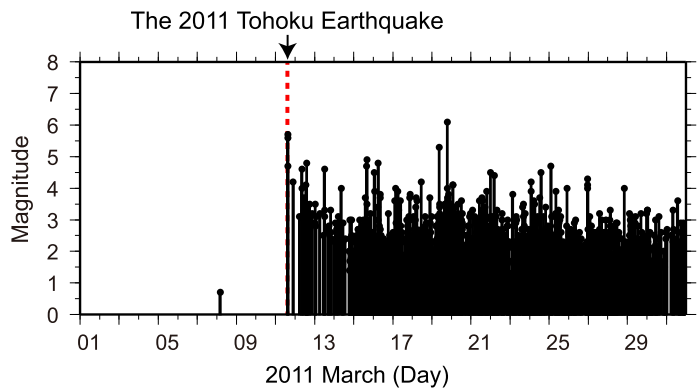

(b)

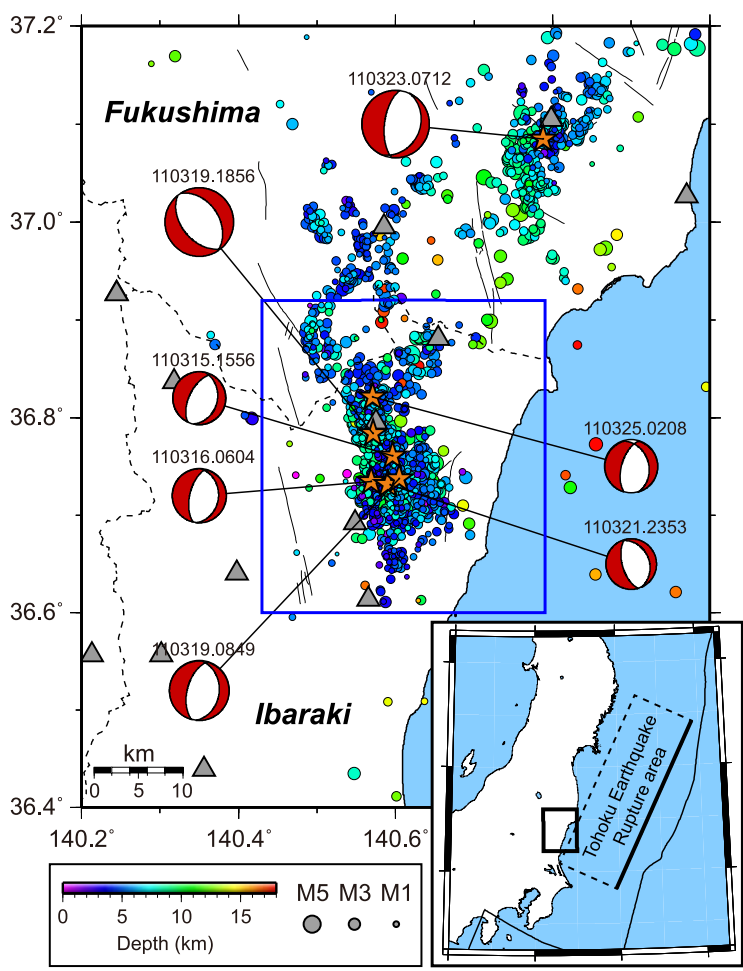

Fig. 1. (a) Temporal changes in the magnitude of earthquakes occurring in northern Ibaraki Prefecture (JMA catalog within in the blue rectangle in Fig. 1(b)). The red broken vertical line is the origin time of the 2011 off the Pacific coast of Tohoku Earthquake. (b) Map of the hypocenters and seismic stations in northern Ibaraki Prefecture and southern Fukushima Prefecture. Earthquakes are shown as circles scaled according to magnitude and color coded with depth. The moment tensor focal mechanisms of large events (NIED) are plotted with the origin time. The gray triangles are permanent continuous seismic stations. Active faults are shown by gray lines. The blue rectangle indicates the location of Fig. 2(a). The broken lines are borders between prefectures. The inset shows the location of the studied area and the rupture area of the 2011 Tohoku Earthquake.

tensional deformation within the overlying plate.

\section{Data and Methods}

Online seismic networks have been put into operation on the northern part of Ibaraki Prefecture by NIED (National Research Institute for Earth Science and Disaster Prevention) and JMA (Figs. 1 and 2). Three seismic stations lie above the seismic source region, providing good constraints on the hypocenter positions. We used arrival times picked manually by JMA and waveforms retrieved by a total of 17 online seismic stations in the study area. The waveform data were recorded at a rate of $100 \mathrm{~Hz}$.

In this analysis, we used the 764 earthquakes, which are listed in the JMA catalog (for the period between 18:00

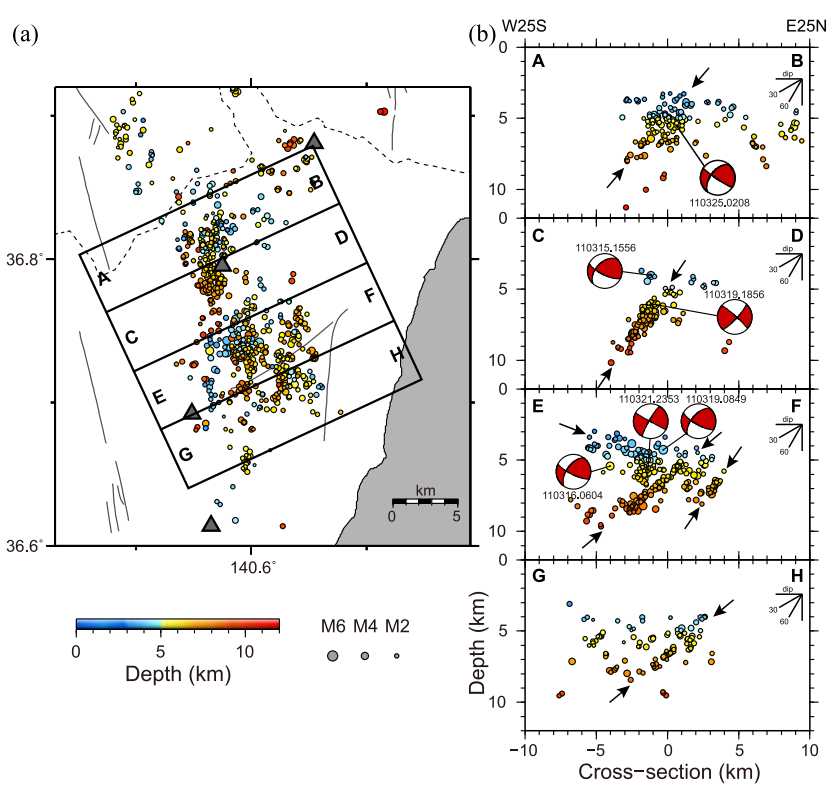

Fig. 2. (a) Map of relocated earthquake hypocenters (scaled according to earthquake magnitude and color coded with depth) within the area outlined by the blue rectangle in Fig. 1(b). (b) Depth sections of relocated earthquakes in each box shown in Fig. 2(a). The strike of the cross section is W25S-E25N, an orientation selected to be roughly perpendicular to the strike of the nodal planes of the large events (refer to a moment tensor solution of each event shown using a lower hemisphere projection rotated into the plane of the section). Clear eastwardand westward-dipping alignments of earthquakes are indicated by black arrows.

14 March and 23:59 31 March (JST)); the number of $P$ and $S$-wave arrival times for each event exceeded 12 and 6 , respectively.

To determine the detailed hypocenter distributions in the source region, the double-difference relocation method (Waldhauser and Ellsworth, 2000; Zhang and Thurber, 2003) was applied to the $P$ - and $S$-wave data. 'Double difference' denotes the difference between the observed and calculated travel time of two events obtained at a particular station. The double-difference method enables us to accurately determine the relative locations of the hypocenters. The relocated hypocenters were calculated assuming a onedimensional velocity structure estimated by JMA (Ueno et al., 2002).

We used differential arrival times obtained for the manually-picked and waveform correlation data. The differential arrival times for the manually picked $P$ - and $S$ waves were 79,026 and 68,408, respectively. Waveform cross correlation in the time-domain (Schaff et al., 2004; Kato et al., 2006) yield a more accurate data set of differential arrival times containing 297,080 $P$-wave observations and 10,6288 $S$-wave observations; all had normalized cross correlation coefficients larger than 0.85 . The correlation measurements were conducted using $1.2 \mathrm{~s}$ window lengths beginning $0.6 \mathrm{~s}$ before the manually picked arrival time for $1-10 \mathrm{~Hz}$ filtered waveforms.

\section{Hypocenter Alignments}

Figure 2 illustrates the distributions of relocated hypocenters at depths shallower than $12 \mathrm{~km}$. The epicentral 
(a)

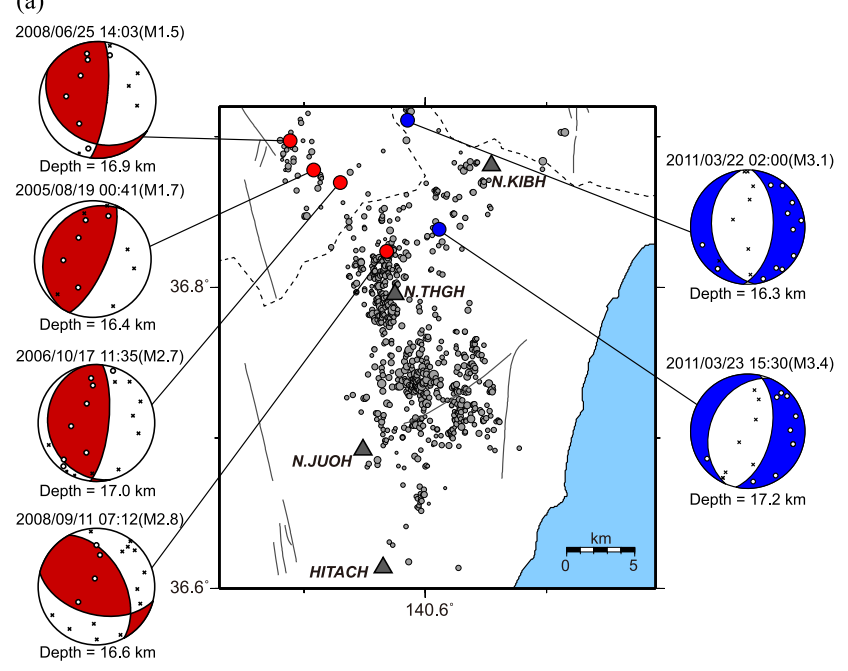

(b)

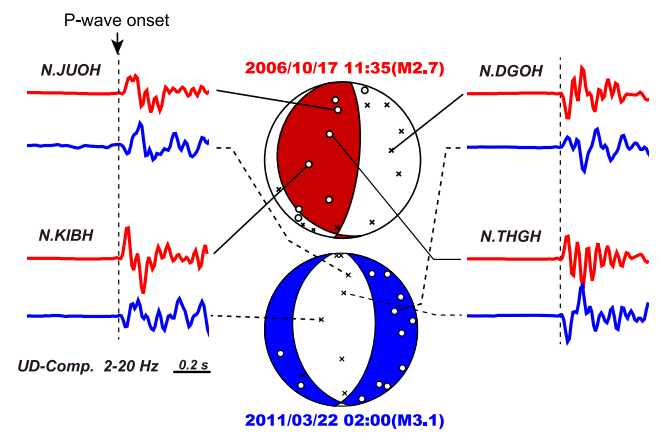

Fig. 3. (a) Focal mechanisms of six earthquakes with magnitude greater than 1.5 that occurred before and after the 2011 Tohoku Earthquake. The origin time, magnitude and depth of each event are denoted above and below each beach ball. The distribution of polarities of $P$-waves is shown as circles (up) and crosses (down). Stations are plotted in lower hemisphere of focal sphere using the equal-area projection. These six events occurred at depths of 16.3 to $17.2 \mathrm{~km}$, which are deeper than aligned hypocenters shown in Fig. 2(b). Gray circles are epicenters of relocated earthquakes in the present study. (b) Examples of 2-20 $\mathrm{Hz}$ filtered waveforms around the $P$-waves for two events, of which focal mechanisms are reverse (red waveforms) and normal faulting (blue waveforms). Each waveform is normalized by the maximum amplitude and aligned at the onset time of the $P$-wave.

distributions are fairly heterogeneous along the seismic sequence (Fig. 2(a)): from the center to the south (E-F, G-H), the epicenters exhibit relatively wide distributions, whereas the epicenters from the center to the north $(\mathrm{A}-\mathrm{B}, \mathrm{C}-\mathrm{D})$ are tightly oriented in a N-S direction.

Depth-sections of the relocated hypocenters from the center to the north reveal an earthquake alignment dipping westwards at an angle from $40^{\circ}$ to $50^{\circ}$ (A-B, C-D in Fig. 2(b)). On the other hand, the hypocenters from the center to the south show a cross-cutting geometry consisting of westward- and eastward-dipping conjugate planes (E-F, G$\mathrm{H}$ in Fig. 2(b)). The dip angles of the hypocenter alignments are roughly consistent with the nodal planes of focal mechanisms of the large events determined by NEID (Figs. 1(b) and 2(b)). The down-dip width of these hypocenter alignments ranges from 6 to $8 \mathrm{~km}$, which is consistent with the typical rupture dimension of magnitude 6 earthquakes (Hanks, 1977).

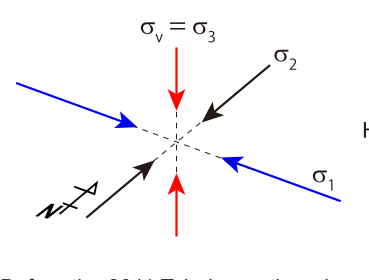

Before the 2011 Tohoku earthquake

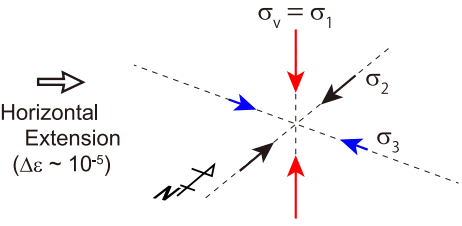

After the 2011 Tohoku earthquake
Fig. 4. Schematic interpretation of the stress change induced by the 2011 Tohoku Earthquake.

The focal mechanisms of the large events represent normal faulting for which the expected orientation of the maximum compressive stress axis is nearly vertical (Fig. 1(b)). The dip angles of each hypocenter alignment (from $40^{\circ}$ to $50^{\circ}$ ) are close to the optimal-orientations with respect to maximum principle stress axis $\left(\sigma_{1}\right)$.

\section{Drastic Stress Change}

To investigate the stress field before the 2011 Tokohu earthquake, we searched the JMA catalog for previous earthquakes in the study area and manually picked the $P$ wave first arrival polarities. We then succeeded determining four focal mechanisms for earthquakes of magnitude greater than 1.5, applying a method developed by Hardebeck and Shearer (2002) to the polarity data. These events occurred at depths of 16.3 to $17.2 \mathrm{~km}$, which are deeper than aligned hypocenters shown in Fig. 2(b). Although the solution quality of these focal mechanisms is not particularly high (solution quality " $B$ " and " $C$ "), but all four mechanisms indicate a reverse-faulting stress regime in the study area, with the $P$-axis oriented in a roughly E-W direction (Fig. 3). In contrast, two earthquakes induced by the 2011 Tohoku Earthquake at the same depths as the previous four events show a normal-faulting stress regime, with the $T$-axis oriented in roughly E-W direction (Fig. 3).

Comparison of the focal mechanisms recorded before and after the 2011 Tokohu earthquake suggests that the stress field abruptly changed from one of E-W horizontal compression to E-W extension in the northern part of Ibaraki Prefecture (Fig. 4). The maximum principle stress axis $\left(\sigma_{1}\right)$ before the 2011 Tokohu earthquake switched to the minimum principle stress axis $\left(\sigma_{3}\right)$. In contrast, the vertical stress (lithostatic pressure), which was the $\sigma_{3}$ axis before the 2011 Tohoku Earthquake, switched to the $\sigma_{1}$ axis afterward while vertical stress stayed constant. A plausible explanation of this pronounced stress change is a significant reduction in trench-normal compressive stress (E-W direction) compared with reduction in trench-parallel stress (N-S direction), caused by the large horizontal extensional deformation within the overlying plate associated with the 2011 Tohoku Earthquake.

We have calculated co-seismic strain changes associated with the 2011 Tokohu earthquake in the study area from continuous GPS network data. The horizontal extensional strain exhibits a step-like increase by approximately $10^{-5}$. Prior to the 2011 Tokohu earthquake, the northern part of Ibaraki Prefecture exhibited E-W contractional principle 
strains produced by forearc deformation accompanying of the Pacific plate. As the secular contractional strain rate increase due to plate convergence is estimated to be about $10^{-7} / \mathrm{yr}$ (e.g., Kato et al., 1998), a straightforward calculation suggests that it will take more than one hundred years to recover the stress change from horizontal extension to compression, during the re-strengthening (healing) stage of the plate boundary fault. It is thus quite important to monitor the temporal change or recover of focal mechanisms in the study area to examine the re-strengthening process on the fault of huge earthquakes.

Acknowledgments. We thank J. Townend and T. Takeda for useful and constructive comments, which led to substantial improvement to the original manuscript. We are thankful to J. Fukuda for fruitful discussion about strain change. We also thank NIED for use of their waveform data, and JMA for use of their waveform data and unified earthquake catalog. Some figures have been produced using the GMT mapping codes (Wessel and Smith, 1991).

\section{References}

Kato, A., S. Sakai, N. Hirata, E. Kurashimo, T. Iidaka, T. Iwasaki, and T. Kanazawa, Imaging the seismic structure and stress field in the source region of the 2004 mid-Niigata prefecture earthquake: Structural zones of weakness and seismogenic stress concentration by ductile flow, $J$. Geophys. Res., 111, B08308, doi:10.1029/2005JB004016, 2006.

Kato, T., G. S. El-Fiky, E. N. Oware, and S. Miyazaki, Crustal strains in the Japanese Islands as deduced from dense GPS array, Geophys. Res. Lett., 25(18), 3445-3448, doi:10.1029/98GL02693, 1998.

Hanks, T., Earthquake stress drops, ambient tectonic stresses and stresses that drive plate motions, Pure Appl. Geophys., 115, 441-458, 1977.

Hardebeck, J. L. and P. M. Shearer, A new method for determining firstmotion focal mechanisms, Bull. Seismol. Soc. Am., 92, 2264-2276, 2002.

Hasegawa, A., K. Yoshida, and T. Okada, Nearly complete stress drop in the $2011 M_{\mathrm{w}} 9.0$ off the Pacific coast of Tohoku Earthquake, Earth
Planets Space, 63, this issue, 703-707, 2011.

Hirose, F., K. Miyaoka, N. Hayashimoto, T. Yamazaki, and M. Nakamura, Outline of the 2011 off the Pacific coast of Tohoku Earthquake $\left(M_{\mathrm{w}}\right.$ 9.0)-Seismicity: foreshocks, mainshock, aftershocks, and induced activity-, Earth Planets Space, 63, this issue, 513-518, 2011.

Ide, S., A. Baltay, and G. C. Beroza, Shallow dynamic overshoot and energetic deep rupture in the $2011 M_{\mathrm{W}} 9.0$ Tohoku-Oki earthquake, Science, doi:10.1126/science.1207020, 2011.

Saiga, A., A. Kato, S. Sakai, T. Iwasaki, and N. Hirata, Crustal anisotropy structure related to lateral and down-dip variations in interplate coupling beneath the Kii Peninsula, SW Japan, Geophys. Res. Lett., 38, L09307, doi:10.1029/2011GL047405, 2011.

Schaff, P. D., G. H. R. Bokelmann, W. L. Ellsworth, E. Zanzerkia, F. Waldhauser, and G. C. Beroza, Optimizing correlation techniques for improved earthquake location, Bul. Seismol. Soc. Am., 94, 705-721, 2004.

Townend, J. and M. D. Zoback, Stress, strain, and mountain building in central Japan, J. Geophys. Res., 111, B03411, doi:10.1029/ 2005JB003759, 2006

Ueno, H., S. Hatakeyama, T. Aketagawa, J. Funasaki, and N. Hamada, Improvement of hypocenter determination procedures in the Japan Meteorological Agency, Q.J. Seismol., 65, 123-134, 2002 (in Japanese with English abstract).

Waldhauser, F. and W. L. Ellsworth, A double-difference earthquake location algorithm: Method and application to the northern Hayward Fault, California, Bull. Seismol. Soc. Am., 90, 1353-1368, 2000.

Wang, K. and K. Suyehiro, How does plate coupling affect crustal stresses in northeast and southwest Japan?, Geophys. Res. Lett., 26, 2307-2310, 1999.

Wessel, P. and W. H. F. Smith, Free software helps map and display data, Eos Trans. AGU, 72, 441, 1991.

Wesson, R. L. and O. S. Boyd, Stress before and after the 2002 Denali fault earthquake, Geophys. Res. Lett., 34, L07303, doi:10.1029/ 2007GL029189, 2007.

Zhang, H. and C. H. Thurber, Double-difference tomography: The method and its application to the Hayward fault, California, Bull. Seismol. Soc. Am., 93, 1875-1889, 2003.

A. Kato (e-mail: akato@eri.u-tokyo.ac.jp), S. Sakai, and K. Obara 